\title{
The Oceanic Imagination: Affects, Surreal Images and Strings
}

\author{
Emily ShuHui Tsai \\ National Chung Hsing University, Taiwan
}

\begin{abstract}
The creative forces of affects are considered to be a mysterious power within our immanence. Although creators exist like lonely islands and may be more vulnerable to poor health, it is problematic to draw an inference that mental illness nourishes creativity. Artists, philosophers, and scientists have to struggle with chaos to create a new vision into their works. This paper argues that first, the creativity of affects is a mysterious power of our immanence, not nourished by pathology; second, the surreal images of curved and juxtaposed spaces by the artists resonate with the scientific experiments conducted by string physicists who propose the existence of multiverse with the possibility of 11-dimensional spaces. Therefore, the creators have shared the equally-important status as the singular beings in their different modes of lives. Deleuze's and Guattari's creative concepts of philosophy help improve the better understanding of the mysterious power of oceanic affects within our immanence. Thus, the general opinion that creativity and mental illness are infamously connected should be entirely re-questioned and re-examined.
\end{abstract}

Keywords: creativity, chaos, affect, surreal images, string, imagination

\section{Introduction}

The creators - artists, scientists, philosophers — exist like lonely islands, undergoing private torments of struggling with chaos to bring forth the new images in the virtual level of imagination that can be actualized into their works. Deleuze, in his essay, "Desert Islands”, mentions three kinds of islands: continental islands, oceanic islands, and the islands in the imaginary. The first two islands are the concrete islands, but the latter is the imaginary one. The feeling toward this imaginary image of the island is ambivalent: It can be a great joy with liberation, or it can express solitude, loss, or isolation. Paradoxically, solitude, and creativity are both mutually exclusive and complementary. The creators in their singular and unique lives with the image of the island have to undergo the process of becoming to flirt with "chaos" ${ }^{11}$ in the virtual level of their imagination. The creators in solitude, drifting away from the dominant social trend, take a transversal path to create their works of "art". Often, before the birth of their great works, the creators are often neglected, forgotten, or sometimes misunderstood as misfits, falling into a temporary state of isolation with poor health. In other words, when their radiating seed is ready to develop something truly new, they fall into a solitary state toward a threshold of chaos where only the true creators dare to move forward without having a breakdown that leads to the pathological state of mental illness. Sometimes, before their masterpieces are born, the creators often have

Emily ShuHui Tsai, Doctorate degree, Associate Professor, National Chung Hsing University, Taichung, Taiwan.

${ }^{1}$ In Deleuze and Guattari's theoretical context, the word, chaos, has a special meaning because they avoid the psychoanalytic terminology of the unconscious. From my viewpoint, the term, chaos, is used in Deleuze and Guattari's context to reinterpret the psychoanalytic concepts of the Freudian unconscious and "the Lacanian Thing". In my understanding, they analyze the same phenomenon of the problem by using their own different terms from the different perspectives. 
to suffer from this isolation, liable for all misinterpretations and misunderstanding, particularly, mental illness.

Generally speaking, when people without a true understanding of what mental illness is encounter the creators who are not so gregarious and often isolated or aloof, they may have held a (mis)belief that there is a connection between the creators and mental illness; that is, they assume that the creators are often regarded as the "tormented genius" suffering from their traumatic wounds. It is a great shock to those who really regard the creators with higher respect and admiration. The controversy lies in the fact that psychoanalysis has its different schools of understanding the unconscious and its treatments to heal the mental torment in different patients have various ways. We are all humans and we can be seriously and emotionally disturbed because of confronting some crucial crises that oppress us with a heavy weight; therefore, we all can be directed to the mental illness if we are unable to manage our emotion while dealing with the frustration. In fact, it is not a big issue; the main problem is that the ideology constructs the lives of mentally-ill patients to be in "the state of bare life", which means the state of social exclusion, in other word, "the symbolic death" in Lacanian sense. It is not only just defamation against all creators, but also the worst "opinion" that circulates among those who do not really understand the struggling process of creativity; thus creativity is mistakenly associated with mental illness for quite a long time. Whenever the creators face the difficult challenges, their emotion can be seriously disturbed but the swinging state of emotional problems is normal. If we have any negative judgement to the swings of emotion which may occur to everyone falling into the unbearable state of fear to feel defeated or excluded, I think this bias should be uprooted entirely from our mind.

I propose that the creators, the works of art and creativity should be viewed separately as the three levels of differences; what I mean is that creativity itself is not essentially derived from the problem of mental illness although all creators, including all of us, may fall into the state of poor health. When a work of art is born, it has its own life, circulating into the markets and receiving criticism, without the control of its creator. Consequently, it is a great joke if those who envy the creators have tried to simulate or even deliberately force themselves to be isolated or appear aloof in order to be "ill”, they may perhaps eventually create nothing but truly become the mentally-ill patients who cannot manage their own disturbed emotion with rationality. To me, this is the worst state of misunderstanding the difference between the creativity and the creators. Truly, creativity is the mysterious forces of individual immanence and the creators can be more vulnerable to the poor health when they need more time to create something truly great. There is undeniable that many creators suffer from the problems of poor health, for example: Isaac Newton, Beethoven, Vincent van Gogh, Ludwig van Beethoven, Edvard Munch, David Foster Wallace, Sylvia Plath, Francisco Goya, Anne Sexton, and Frédéric François Chopin, to name just a few here. However, this may only show that creators are more vulnerable and susceptible to the poor health because they do not pay good attention to any physical exercises to improve their health. On the other hand, there is one question we should take it into serious consideration: There are also many mentally-ill patients who cannot really create anything, and each one of us may perhaps become liable to this state of being, whenever people are defeated by the difficulties of life and he or she is overwhelmed by the inability to develop a good regulation of the emotion with courage. To be more precise, we cannot draw a quick and unreasonable inference that creativity and mental illness are essentially connected.

To Freud, he thinks that art is a self-therapeutic process to heal the inner wounds. Fundamentally, I do not have any good reason to completely deny it. In his short essay, “Creative Writers and Day-Dreaming”, Freud states that the "child's best-loved and most intense occupation is with his play or games" (Freud, 2001a: 143), but this childhood play cannot continue forever and it should be abandoned in adulthood. The problem is that 
the repressed desire does not disappear; it is displaced or disguised as fantasy or day-dreaming. For this reason, what the aesthetic pleasure in creative arts provides is liberating the tensions and sublimating the desire; art viewed in this way is the sublimated form of our repression. For Lacan, all artists attempt to represent the lost Maternal object (the Thing or das Ding); thus this primordial lost Object beyond the pleasure principle functions as a driving force for all creativity of the creators. Heidegger shares the similar belief in "The Origin of the Work of Art", which argues that all works of art reveal "the thingly character" (Heidegger, 1977: 150). In other words, art is the expression of the artists' ontological being. However, Deleuze thinks creativity in a different way and he argues as the following:

We do not write with our neuroses. Neuroses or psychoses are not passages of life but states into which we fall when the process is interrupted, blocked, or plugged up. Illness is not a process but a stopping of the process, as in "the Nietzsche case." Moreover, the writer as such is not a patient but rather a physician, the physician of himself and of the world. The world is the set of symptoms whose illness merges with man. Literature then appears as an enterprise of health: not that the writer would necessarily be in good health, but he possesses an irresistible and delicate health that stems from what he has seen and heard of things too big for him, too strong for him, suffocating things whose passage exhausts him, while nonetheless giving him the becomings that a dominant and substantial health would render impossible. (Deleuze, 1998: 3)

For Deleuze, creativity is not viewed from the perspective of pathology because to create is to take the line of flight to move on toward the trajectory of difference, guided by the imagination, with which artists, philosophers, and scientists, the so-called Chaoids ${ }^{2}$ in Deleuze and Guattari’s context, constantly struggle with the forces of affects in order to bring forth something new. In his dialogue with Claire Parnet, Deleuze complains that Freud has created the notion of an unconscious that "breaks up all productions of desire" and in practice, it "diminishes, destroys and exorcises it" because "the unconscious is understood as a negative and it's the enemy" (Deleuze \& Parnet, 2006: 57). Deleuze and Guattari in Anti-Oedipus also argue that the unconscious is a production of desiring-machine because "A machine may be defined as a system of interruptions or breaks" (Deleuze \& Guattari, 1977: 36). The desiring-machine in its own creativity works when it breaks away from the old connection to create something new. With this new conjunction, it denies the Freudian myth that the unconscious is the metaphysical theatre of the familial tragedy, a dark storage of traumas. Deleuze and Guattari create an argument from the different perspective to mitigate the deadlock, stating that in the virtual level of chaos, where the creative and affirmative forces of affects dwell, they undertake no return to origins (Deleuze \& Guattari, 1994: 174).

There are two chapters in this short paper: The first one focuses on the difference between creators and patients: The former can break through the engulfing forces of chaos to create something truly new and the latter just breaks down and fails to do anything. For this reasoning, the psychiatrist's understanding of creators related to the mental illness is questioned and this idea is reinterpreted by Deleuze and Guattari. The second chapter discusses some surreal images which surprisingly resonate with the cosmic poetics of the string physicists. Anyone with the knowledge of string theory can hardly think of it as science, but rather view it as something magical and imaginary like cosmic poetry. The string scientists understand the universe as a giant orchestra played by the strings, the smallest and fundamental element of cosmic vibrating forces, which can be understood as similar to the Deleuzian notion of affect, a creative force within our immanence from my

\footnotetext{
${ }^{2}$ In the theoretical book, What Is Philosophy? by Deleuze and Guattari, it describes that "In short, chaos has three daughters, depending on the plane that cuts through it: these are Chaoids—art, science, and philosophy—as forms of planes that cut through the chaos in different ways (What Is Philosophy?, 208).
} 
viewpoint. The string theorists claim that space itself can be warped and curved with a juxtaposition of multi-layered spaces; their cosmic images of space show certain similarity with the images of multi-layered spaces created by some surreal artists. Consequently, there is no simple coincidence that the string theory of science and the surreal images of art have arrived at such a point of convergence regarding the deeper structure of cosmic poetics as if the human mind reveals the whole secrecy of the cosmic hidden truth. This is the charm of creative and affirmative affect in Deleuze's and Guattari's theory.

\section{Affect, Imagination, Immanence}

Affect in Freudian context is seldom regarded as the creative force, but related to the repressed emotion of the unconscious. However, the creative imagination is often regarded in Deleuze and Guattari's theories as a mysterious and immanent power. In Deleuze's theoretical framework, "artists are presenters of affects, the inventors and creators of affects” (Deleuze \& Guattari, 1994: 175). Within this new theoretical understanding, we could reinterpret, redefine, and deconstruct what once troubles art tinged with pathology. To fight against the deep-seated notion that the unconscious breeds negative and destructive forces, engulfing us in its dark torments, Deleuze and Guattari have tried to use the term, the virtual, to further revise and improve the Freudian unconscious, and affirm the positive energy of affect as the potentially-creative forces.

The term, affect, as proposed by Spinoza, is often understood as bodily intensities or life forces within the immanence. Deleuze, influenced by Spinoza, does not want it to neither correspond to the Freudian notion of libido energy of impulses nor to the Lacanian notion of the Real, the energy forces of destructive tendencies. Deleuze elaborates that there is a difference between affection (affectio) and affect (affectus). Affect is a non-representational mode of thought. In other words, affects at the pre-individual level are within a zone of indifferentiation where the artists experience forces of sensation. This is approaching the threshold of chaos that invites creators to swim through a zone of indetermination, of indiscernibility. It is the breaking point, preceding all natural differentiation, where things and animals, as nonhuman forces incessantly approach.

Deleuze and Guattari further explain that "perhaps art begins with the animal” (Deleuze \& Guattari, 1994: 183). The idea of the animal in this context does not actually mean the animal in the natural environment, but rather refers to the affect, the nonhuman or cosmic forces, the infinite speeds and intensities that creators are capable of feeling under certain conditions within immanence.

Percepts are no longer perceptions; they are independent of a state of those who experience them. Affects are no longer feelings or affections; they go beyond the strength of those who undergo them. Sensations, percepts and affects are beings whose validity lies in themselves and exceeds any lived ... Affects are precisely these nonhuman becomings of man, just as percepts—including the town—are nonhuman landscapes of nature ... We are not in the world, we become with the world; we become by contemplating it. Everything is vision, becoming. We become universes. Becoming animal, plant, molecular, becoming zero. (Deleuze \& Guattari, 1994: 164, 169)

As mentioned above, when artists are quite self-absorbed and strongly affected by certain objects of nature, like flowers, trees, dolphins, cats, or birds, etc., affects as the nonhuman forces in the virtual level start to generate completely the new images in our mind. In this encounter, affects are transmitted from one body to the other body; artists' minds are transported into a state of sensation to struggle with chaos. Deleuze and Guattari discuss this state of being affected in the process of becoming, by using several examples - the captain Ahab in Moby Dick by Herman Melville, the characters in André Dhotel's novels, and the main characters in The Unnamable by Samuel Beckett-in the process of becoming-animal, becoming-plants, and 
becoming-imperceptible. It is approaching the threshold of the chaos in the virtual that gives rise to the creative inspiration for all creators. When Deleuze mentions that "affects are precisely these nonhuman becomings of man", the notion of nonhuman here is quite different from "inhuman" which would refer to the destructive and incontrollable forces or impulses for the evil damages. For Deleuze, the word "nonhuman" refers to the creative forces of affects related to the cosmic power as singularity in the virtual level within our immanence, which means it stays at the pre-individual, and is thus regarded as impersonal.

Let's take Bacon's figuration of "the Figure" in his painting for an example to further understand the nonhuman forces of affects. In The Logic of Sensation, Bacon is interpreted as the painter of the heads, not faces. The deformation of the head is the material of the Figure, which refers to the body; he tries "to dismantle the face, to rediscover the head or make it emerge from beneath the face” (Deleuze, 2004a: 19) and actualizes the abstract images between man and animal. What Bacon has tried to show is the abstract and blurring images of Figure in the virtual before its actualization (figuration) in the concrete images. In other words, in his painting, Bacon reveals the abstract images of "the Figure". The creative act is a becoming-nonhuman process of rendition: to render visible the virtual affect, to render perceptible the impersonal, and to render conceptual the ontological being.

Another expression of the enchanting marvel of the nonhuman affects can be also revealed in the reveries of becoming-child; to be more precise, it is the reawakening moment of childhood innocence within immanence. Influenced by the Bergsonian concept of duration of time that the past coexists with the present, Deleuze in Cinema 2, discusses Fellini by quoting his statement that "We are constructed in memory; we are simultaneously childhood, adolescence, old age and maturity” (Deleuze, 1989: 99). As the contemporeinity of the past and the present, our hidden childhood innocence can be reawakened at the certain crucial moment. This childhood innocence that exists within our immanence is considered as pure power and even bliss as Deleuze discusses it in Pure Immanence (Deleuze, 2001: 30). Such childhood innocence could be reawakened by the animal images or the charming objects of nature that function as poetic muses for creative inspirations: for example, the nonhuman images, such as cute animals and cosmic objects, created by the well-known Taiwanese artist, Jimmy Liao, and the prose writing on cetacean imagination by Hung-Chi Liao. Both of them in their creative works reveal how nonhuman images function as their creative inspiration for their creative art. Like most of the artists, both of these two artists have been living in their "lonely islands" in the imaginary before their masterpieces are born; the radiating seeds affected by the nonhuman forces of childhood innocence in their immanence blossom into their works of art. Truly, the artists must go beyond what has previously been thought, or sought; they must feel compelled by their inner gravitational pull of aesthetic sensation to approach the threshold of chaos in the virtual state of imagination. In other words, artists in their creative process have fallen into the state of becoming. Becoming does not mean imitation or identification, nor does it indicate evolution, but rather involution. The Deleuzian concept of becoming does not mean to become "something" other than the self, or a total loss of the self. Deleuze argues that,

Becoming is an extreme contiguity within a coupling of two sensations without resemblance or, on the contrary, in the distance of a light that captures both of them in a single reflection...it is a zone of indetermination, of indiscernibility, as if things, beasts, and persons endlessly reach that point that immediately precedes their natural differentiation. This is what is called an affect. (Deleuze \& Guattari, 1994: 173)

Within the Deleuzian theoretical concepts of becoming and affect, we can see how in the creative process, the 
object provides itself as the imaginary vehicle that transports the artists to the limit of their consciousness, the threshold of chaos, to bring back the new visions to create their masterpieces. The becoming experience reaches this indiscernible and indeterminate inter-zone where the creative forces of affects dwell. In other words, the idea of becoming-child does not mean to regress to become an annoying child, in the state of which the childhood innocence is negatively understood as ignorance and childishness in need of maternal protection and paternal guidance.

In my discussion, the affirmative forces of creative affect in the process of becoming-child and becoming-animal for creativity, not only in art, but also in a different mode of life, refer to a transversal progress into an elevated state of inner strength, intellectual maturity, wisdom and love with the reawakened sense of childhood innocence. The issue is that the childhood innocence should not be regarded the same as the childhood experiences; creators do not actually create works of art, merely based on childhood memories. Deleuze elaborates:

It is true that every work of art is a monument, but here the monument is not something commemorating a past, it is a bloc of present sensations that owe their preservation only to themselves and that provide the event with the compound that celebrates it. The monument's action is not memory but fabulation. We write not with childhood memories but through blocs of childhood that are the becoming-child of the present. (Deleuze \& Guattari, 1994: 167-168)

Deleuze interprets that the creativity of art is not entirely based on the memory of the past and it is his theory of difference, breaking away from the Freudian conventional understanding that healing the inner wounds is the driving force for artists to create their works of art. If art is merely considered as the unconcealedment of symptoms and an aesthetic display of individual pathology, nobody would like to do any creative works of art to win empathy and compassion or even worse, to receive unknowingly a cynical disdain or a simmering contempt from others.

Thinking of the creators in the state of "lonely island", always submerging themselves in their struggling sentiments to break away from "opinions" or "clichés" to flirt with chaos without being engulfed entirely in delirious fantasy or madness, they follow their oceanic imagination that swims through the unfolding waves of affects as if the mind is a virtual organ of thinking being - the brain-subject—with its own creative life. Most of the time, people need a protective umbrella to shield them from falling into chaos but the creators have chosen the untrodden path to struggle with chaos to bring forth a new vision. As $I$ is an other, this fractured $I$ with his unknown and unnameable otherness is constantly disturbed by his inherent double structure: On the one hand, he is seduced by the competition in the society of neoliberal capitalism to survive well; on the other hand, he is compelled by the unsettling pull to reunite with the truth of the selves. This virtual otherness in the fractured $I$ is the chaos where the affirmative forces of oceanic affects imperceptibly emit "an inner calling" for $I$ to embrace the new reunion of the selves.

"The oceanic feeling" interpreted by Freud when he analyzes religious believers is understood as the feeling of inner unbounded limitlessness, a sense of wholeness with the universe. Freud misinterprets it as an infantile yearning for the authority of paternal protection, a strong umbrella to shield them from the suffering and anxiety of existence. Under this context, "this oceanic feeling”, is understood as a regression to immaturity, the state of which creates "the weak life" to people because of their surrendering will to a powerful figure of authority. This is their illusion of pathology. But for creators, "the oceanic affects" of chaos within their immanence function as a springboard to elevate them to another new plane for a new form of "art" as their 
creative novelty. Moreover, to Guattari, this unknown and unnameable zone of oceanic forces, full of pure singularities, does not indicate destructive forces that schizophrenia would experience:

Chaos is not pure indifferentiation; it possesses a specific ontological texture. It is inhabited by virtual entities and modalities of alterity which have nothing universal about them. It is not therefore Being in general which irrupts in the chaosmic experience of psychosis, or in the pathic relationship one can enter into with it, but a signed and dated event, marking a destiny, inflecting previously stratified significations. (Guattari, 1995: 81)

This impersonal level of chaos bears the mystery and secrecy of our ontology. In What Is Philosophy? Deleuze and Guattari argue: "Art is not chaos but a composition of chaos that yields the vision or sensations, so that it constitutes, as Joyce says, a chaosmos, a composed chaos—-neither foreseen nor preconceived” (Deleuze \& Guattari, 1994: 204). Art certainly does not refer to chaos of the mind. In fact, the compositions of art should be based on rational management of the creative affects even though the creators in this condition seem to appear to fall into a state of aesthetic sensation, which could be misinterpreted as a state of being in "the lonely island" with poor health from the perspective of those non-creators.

Artists have to feel traversed incessantly by the speeding intensities of the deterritorialized flows of affect within the body; they feel compelled to be carried away by the forceful sensation of oceanic affects envisioned in their images of thought to create art. Yet, the artists could break through the engulfing forces of speeding affects within the mind, whereas the patients of mental illness could just break down and create nothing. In other words, the work of art might express "psychotic", "paranoiac", or "hysterical” phenomenon, but it does not indicate that artists themselves must have suffered from such mental illnesses in order to create these images. In other words, as Ian Buchanan explains, "The schizophrenic process is not the same thing as schizophrenia, the illness” (Buchanan, 2008: 40). The schizophrenic process reveals how desire works as a synthetic process and it is the state of sensation the artists have to struggle through in their delirium from which "it lays bare the material process of the unconscious" (Buchanan, 2008: 40). To be more precise, in the schizophrenic process, the artists in their "lonely island" struggle with great efforts to actualize the oceanic forces of the virtual chaosmos of the mind into the images of thought or art to compose their masterpieces. Thus, it is a great danger to think that the creative inspiration is derived from the mental illnesses.

\section{Chaos, Surreal Images and Strings}

As the unfolding process of oceanic affects worked by the "unnameable" brain-subject in chaos of the virtual, which of course, unbeknown to the creators themselves in the conscious level, Deleuze and Guattari think artists and scientists present their art in different ways: The former brings back from chaos "variables"; the latter brings back "varieties" (Deleuze \& Guattari, 1994: 202). Somehow, from the contemporary string physicists' view of the hidden structure of the universe, the cosmic images they have created are as fantastic and marvellous as those surreal images created by the artists. When we view certain surreal images that are so ethereal or weird beyond our understanding, particularly those in which the multi-layered spaces have been juxtaposed onto a two-dimensional space of canvas or photographs, this powerful imagination is frequently regarded as "nonsensical", or "illogical" beyond our comprehension. These images are treated as the pure pleasure of aesthetics. But it is a stunning surprise that the contemporary string physicists and the surrealists have arrived at a certain point of convergence that they both show "aesthetics of cosmic imagination" like poetry. Because nothing could be proved as "absolute truth", neither can we conclude that the cosmic images visualized by string physicists are entirely false, representing nothing scientific but pure imagination. 
Brian Greene and Michio Kaku are American theoretical physicists and string theorists. Their concept of "string theory" is remarkably provocative, and might suggest that scientists' imagination is not less fantastic than that in the artists when both of them attempt to seek for the truth of "the reality". The string theorists draw their inference that there are additional dimensions of space, existing beyond this universe, which means there would be multi-verse, or parallel universe, instead of just one universe. The string theory tries to provide a new answer to the question of what the smallest and most indivisible constituent of matter would be. The conventional idea is that "matter is composed of particles—electrons and quarks—that can be modelled as dots that are indivisible and that have no size and no internal structure” (Greene, 2004: 17). In fact, every particle is "composed of a tiny filament of energy" and it is shaped like a little string (Greene, 2004: 17-18). And I would like to link "this little string" with Deleuzian notion of affect, the creative energy force vibrating within the immanence of our body.

To those string theorists, the whole universe is an elegant orchestra concert hall and the smallest element of each matter is a "string", which seems to resonate a lot with the vibrating life energy, the creative forces of affects. We could affect and get affected by the invisible forces of the objects in the universe. By using a theoretical framework of quantum physics and theories of relativity, the string theorists believe that two objects within a long distance would still feel close to each other. It explains well the possibility of transmission of affects between two humans or objects even though they are far away from each other. For example, the leaves of the trees are affected by the sunlight so that they are empowered to create more life energy for their own growth. We humans can be unknowingly affected by the invisible gravity of the moon which can be affected by the gravitational pull of other planets too. The moon affects the earth; this phenomenon can be seen in the tidal waves of the ocean; when the moon is approaching its full state, humans can feel imperceptibly affected by the unstable swings of their emotion because the major component of the human body is water. Drawing from this inference, the earth itself can affect and be affected by all gravitational forces from other galaxy too. This is how "the cosmic orchestra" has created an imperceptible impact on us beyond our own awareness.

The most amazing discovery in string theory is the issue of space and time; the string theorists even think that there might be eleven dimensions in the universe (Greene, 2004: 18). If this unbelievable cosmic poetics is created by the imagination of artists, perhaps, the reviewers would merely see it as an aesthetic pleasure. But on the other hand, if these surreal images suddenly can correspond to those explained by the string theorists, people with the rational mindset can still think that it is just a mere speculation. The string theorists try to prove from general relativity that the effect of gravity would cause space to warp, or to curve on itself: "General relativity provides the choreography for an entwined cosmic dance of space, time, matter and energy" (Greene, 2004: 72). The reason for this inference is that "space-time and, in particular, the way it warps and curves, is an embodiment of the gravitational field" (Greene, 2004: 75). In other words, the space is entangling itself in accordance with the rule of gravity. This is the main reason for the string theorist to claim boldly that two objects within a long distance could really affect each other.

Two things can be separated by an enormous amount of space and yet not have a fully independent existence. A quantum connection can unite them, making the properties of each contingent on the properties of the other. Space does not distinguish such entangled objects. Space could not overcome their interconnection. Space, even a huge amount of space, does not weaken their quantum mechanical interdependence. (Greene, 2004: 122)

My argument here is not to prove whether the string theorists' inference is the right way to understand the truth 
of the images created by the surreal artists. My main point is to show that however wild or unbelievable their imagination may seem to us, we would better not always regard the artists' imagination as nothing more than the pure pleasure of poetic fantasy. Perhaps, the string theorists can take seriously the wild imagination presented by the surrealists' arts that show a different view of cosmic hidden reality. This is something very important which the psychiatrists often ignore.

Deleuze in his book, Foucault, shares a similar view that the most exterior object might be felt to be existent in the most interior part of the subject. It shows a certain converging correspondence with the string theorists' ideas that two objects, the one with its double, could affect or get affected mutually beyond the limitations of geographical territories. We could never fully realize that our sudden unexplainable intimate "feeling" within immanence could be subtly affected by an object or a person that is so far away from us as if it existed within us. This intimate mystery provokes or challenges our thinking or imagination as if there were a certain alien object of "unthought" within thought that existed inclusively in our immanence. Deleuze elaborates on this idea arguing that this unthought element, which is outside the most intimate exteriority, constructs "an inside-space that will be completely co-present with the outside-space on the line of the fold" (Deleuze, 1988b: 118). Moreover, Foucault, in his book, The Order of Things, discusses "man and his doubles”, writing that "man, in the analytic of finitude, is a strange empirico-transcendental doublet ..." (Foucault, 1974: 318). Foucault believes that there is a void that could not be integrated into the discursive framework; thus, it is considered as "unthought" and it represents the unknown otherness that exists within immanence. This is how Deleuze explains the concept of vibrant affects which does not refer to the conscious level of affection: There exists in chaos the brain-subject as the pure form of alterity thinking in itself for creativity (Deleuze \& Guattari, 1994: 211). The unthought element that forms this fractured $I$ is a creative energy, affect, or a life force within our immanence. To be more precise, this unthought within thought itself nourishes the concept of fractured "I" and fosters the becoming process of unfolding and folding, that is, from the virtual to the actual. Somehow, in the interior mindscape within the selves, the most distant as the unknown could be proved as the most intimate and the most interior. It is this unnameable interior mindspace that gives rise to the creative forces and also allows the selves to undergo the process of becoming with our will. It seems that the space(s) contracted in multi-levels within the human mind is quite similar to the warped spaces of multiverse.

When we view the photographic images created by Jerry Uelsmann, an American photographer, we may feel that the space presented in each photographic image is quite multi-layered, based on a juxtaposition or contraction of multi-dimensional spaces. This creates an aura of the surreal images in the two-dimensional space of the photography and inspires a stunning vision of dream-like awe. Indeed, within this two-dimensional space, the viewers feel something ethereal coming from an exterior space to violate the two dimensions. The surreal images in his art of photography with an aesthetic appeal seduce us to think the alternative truth of reality beyond our comprehension. For example, one surreal image of his photograph shows a human palm, but what we see in the palm is the clouds moving in the sky and a house standing in front of a man as if there were simultaneously many different spaces that converged on one another. On the other hand, our understanding and logical reasoning tell us that a human palm could not show clouds in the sky and a house could not exist in the clouds. There are three different spaces that have converged here at one point as if their different spaces crushed into one another. Another example from his photographic art shows a river flowing through a beautiful valley, but the way the river flows is like an image of a woman's body lying there in the valley in a rather sensual and seductive way. 
To me, this virtual level of the cosmic images is the level of the unnameable and the unknown, or in Deleuzian term, the mystery of the oceanic affects. Chaos is in the virtual wherein the creative power of the affirmative forces of affects dwells; however, to involuntarily break into the threshold of chaos is quite often understood merely as suffering from the mental illness, as explained by the Freudian term, "schizophrenia". Indeed, a schizophrenic is a patient whose consciousness is violated by the unconscious forces with a result that he tends to lose his sense of reality. In Deleuzian sense, a schizophrenic is a weak person whose desiring-machine breaks down when he/she is entirely overwhelmed by the engulfing forces of chaos. On the contrary, the creators are those whose mind can break through the engulfing forces of chaos, from which they create a new vision, a new form of art. However, it does not mean that the creators have to fall into the process of becoming-schizophrenic in order to create something new. The main issue is that we should stop labelling the creators, especially artists and poets, as the patients of mental illnesses.

Being accused of reduction, Freudian psychoanalysis tends to describe the unconscious with negative and destructive forces, rather than positive and affirmative forces. We know that indeed this pre-language or impersonal level, to Freud, the unconscious, and to Deleuze and Guattari, the chaos in the virtual, is the dangerous zone within the subject, because it would either force the subject to become mentally ill if his mind is overwhelmed and conquered by the engulfing forces of chaotic seduction. The Deleuzian theories on immanence helps shed some light on the creative forces of affects in a positive way with his revision. Even within this virtual dimension of chaos, the artists' imagination should not be regarded simply as a fleeting illusion that shows nothing but a pure pleasure of aesthetic fantasy. If we look to the string theorists' ideas, quantum mechanics can provide us with a more "poetic" and more "artistic" world view than most scientists could imagine. These string theorists' imagination is not less powerful and poetic than that of artists or poets, though there truly exists secrecy within the deeper structure of the universe beyond our human understanding. Therefore, the imagination in artists' creativity should not be only reduced into an understanding of pure pleasure that sublimates repressed desire into the work of art, healing the inner wounds.

\section{Conclusion}

The mystery of the oceanic energy forces in chaos working within immanence in different ways for the chaoids, the three daughters of chaos, invites us to become more curious about the ontological secrecy of the brain-subject, as the other thinking being itself in the fractured $I$. Yet, it is a great danger to privilege this virtual level of chaos over the importance of our own consciousness. We need a certain order in our life to govern the uncontrollable forces of chaos with our inner strength, so that our desiring-machine will keep moving on to search for the new "vision" for a new mode of life. The creative forces, regarded as a mystery of immanence, are not derived from the mental illnesses. The mental illness is the state of stagnation or immobility, in which the patients are unable to take the line of flight to move on their life for a more positive and creative way. That is, mental illness is the break-down of desiring machine which gets trapped in the psychic wounds.

The controversy between mental illness and creators really damages and undermines the dignity and value of creators. It is better for us not to be influenced by psychoanalysts and psychiatrists who attempt to regard art as an aesthetic presentation of how artists deal with their symptoms or pathological fantasy; To be more precise, art is merely a sublimated form of repressed desire and traumatic memory. On the other hand, "mental illness" is not often caused by or derived from the patients' pathological history of their unknown individual immanence; the mental illness can be caused by the oppressively-rigid social systems based on the collective 
fantasy or ideology that regulate people in a bad and unequal way. People who could not fit into the oppressive social systems based on "the collective fantasy or ideology" may fall into the state of depression; thus, it shows their desiring-machine breaks down and becomes mentally-ill.

Deleuze and Guattari's theories on art, affect, and chaos help clarify the problematic opinion that creativity is linked with mental illness. The internal world of immanence has its own "virtual universe" that conceals the mystery of creative affects and the individual secrecy of ontology. For Deleuze, the virtual is the level full of potentially creative forces of life and this impersonal and pre-linguistic level indicates an affirmative energy of life that has a status of transcendental values, as he states that "it appears therefore as a pure stream of a-subjective consciousness, a pre-reflexive impersonal consciousness, a qualitative duration of consciousness without a self” (Deleuze, 2001: 25).

Against the Freudian biased interpretation that "the oceanic feeling" is often understood as a regressive infantilism in search of protection of paternal authority, I use this phrase, the oceanic imagination, arguing that the oceanic affects of chaos in a more creative sense give rise to the actualization of the virtual images. Psychoanalysis focuses too much on pathology, not on creativity; as such, it could render the creativity of art pathological. It is very unfair for those who want to create all forms of art, because they can be inevitably labelled as the patients of mental illness. It not only discriminates and humiliates but also denigrates the power of creativity as well as the potential creators.

The deep-seated psychiatric "ideology" that pathologizes the works of art should be entirely re-questioned with a new evaluation because the creative forces are the secrecy of the individual immanence. To be more precise, the patients of mental illness are different from the creators. Patients are those who get stuck in their fixation of traumatic memories and experience a breakdown, but the creators with bad health can still create, and their desiring-machine could still work well to create "a new vision” out of chaos. Before the birth of great masterpieces, those creators truly exist like lonely islands. Correspondingly, the deeper structure of the whole universe itself is the great mystery of "the celestial mind"; the string theorists have tried to explore the truth of the deeper structure of the universe with their celestial poetics in wonder like a great piece of art, which is similar to the artistic works that reveal the surreal imagination of the artists and the poets. Therefore, to me, the chaoids, the three daughters of chaos—artists, philosophers, and scientists-have shared the equally-important status as the singular beings in their different modes of lives.

\section{References}

Buchanan, I. (2008). Deleuze and Guattari's Anti-Oedipus: A Reader's Guide. New York: Continuum.

Deleuze, G. (1988a.). Bergsonism. New York: Zone Book.

Deleuze, G. (1988b). Foucault. Trans. Seán Hand. Minneapolis: University of Minnesota Press.

Deleuze, G. (1988c). Spinoza: Practical philosophy. Trans. Robert Hurley. San Francisco: City Lights Books.

Deleuze, G. (1989). Cinema 2. Trans. Hugh Tomlinson and Robert Galeta. Minneapolis: University of Minnesota Press.

Deleuze, G. (1998). Essays Critical and Clinical. Trans. Daniel W. Smith and Michael A. Greco. London: Verso.

Deleuze, G. (2001). Pure Immanence: Essays on A life. Trans. Anne Boyman. New York: Zone Books.

Deleuze, G. (2004a). The Logic of Sensation. Trans. Daniel W. Smith. Minneapolis: University of Minnesota Press.

Deleuze, G. (2004b). Desert Islands and Other Texts. Trans. Michael Taorminad. Ed. David Lapoujade. Los Angeles: Semiotext(e).

Deleuze, G., \& Guattari, F. (1977). Anti-Oedipus: Capitalism and Schizophrenia. New York: The Viking Press.

Deleuze, G., \& Guattari. F. (1994). What Is Philosophy? Trans. Graham Burchell and Hugh Tomlinson. London: Verso

Deleuze, G., \& Parnet, C. (2006). Dialogues II. Trans. Eliot Ross Albert. New York: Continuum.

Foucault, M. (1974). The Order of Things. London: Routledge. 
Freud, S. (2001a). “Creative writers and day-dreaming”. The Standard Edition of the Complete Psychological Works of Sigmund Freud, 9 (1906-1908). Trans. James Strachey. London: Vintage, 144-146.

Freud, S. (2001b). “Civilization and Its Discontents”. The Standard Edition of the Complete Psychological Works of Sigmund Freud, 21 (1927-1931). Trans. James Strachey. London: Vintage, 64-72.

Greene, B. (2000). The Elegant Universe: Superstrings, Hidden Dimensions, and the Quest for the Ultimate Theory. New York: Vintage.

Greene, B. (2004). The Fabric of the Cosmos: Space, Time, and the Texture of Reality. New York: Vintage Books.

Guattari, F. (1995). Chaosmosis: An Ethico-Aesthetic Paradigm. Trans. Paul Bains and Julian Pefanis. Indianapolis: Indiana University Press.

Heidegger, M. (1977). Basic Writings. Ed. David Farrell Krell. New York: Harper \& Row.

Kaku, M. (1994). Hyperspace: A Scientific Odyssey through Parallel Universes, Time Warps, and the 10th Dimension. New York: Anchor Books.

Spinoza, B. (1992). Ethics. Trans. Samuel Shirley. Ed. Seymour Feldman. Indianapolis: Hackett Publishing Company.

Sussman, A. (2007). "Mental Illness and Creativity: A Neurological View of the 'Tortured Artist'”. Stanford Journal of Neuroscience 1.1 (2007): 21-24.

Szasz, T. (1985). “Intentionality and Insanity: Some Lessons on Reflections on Art”. Literature and Medicine. 4 (1985): 1-12. 